\title{
The dancer at work: The aesthetic and politics of practice clothes and leotard costumes in ballet performance
}

\begin{abstract}
This article focuses on the aesthetic implications innate to the introduction of tightfitting rehearsal-style costume, a leotard, to the dance studio and stage. In ballet, the pared-down and subtle design of such costumes is found in many dance works from the twentieth century until today, including the 'black and white ballets' by George Balanchine, or 'ballet-ballets' by William Forsythe. These works are also considered plotless and seem to deter the viewer from the theatrical conventions of plot lines, characters and narratives. This article is concerned with that which is highlighted in such works: the dancer's moving body and the leotard as a costume that particularly refers to the performer at work and in own cultural setting. The look into the relationship between the dancers and leotard as a costume type communicates important information about the performer's work and their development of roles in such repertoire. The closer consideration of this relationship in reference to the aesthetic of practice-clothes ballet also discloses plenty about the artistic potentials in such choreography and performance, revealing how the use of leotard as a stage costume has both furthered and challenged some of ballet's traditions and cultural conventions.
\end{abstract}

\section{KEYWORDS}

leotard

ballet

dance

black and white ballet leotard ballet practice-clothes ballet Forsythe

Balanchine

1. The Oxford Dictionary defines 'body suits' in implicit associations with sports, while 'leotards' are positioned in reference to dance (see Oxford Dictionary of English 
2010, 3rd ed.]). This is why I adopt term 'leotard' as more appropriate to discuss the dance costume type.

2. The Romanticism introduced long scenes, or whole acts, of highly structural choreographic divertissements for the ensemble, and they followed in the late-nineteenth century classicism of Petipa. They are performed in uniform white soft, gauzy tutus, as explained by historian Arnold Haskell quoting Romanticist Teophile Gautier: "[t]his new style brought about a great abuse of white gauze, of tulle and tarlatans, shadows melted into mist through transparent dresses. White was almost the only colour used' (in Haskell 1947-1948: 43) hence the genre of ballet blanc.

3. Elaborately designed original Concerto Barocco of 1941, on entering the repertory of the Ballet Russe de Monte Carlo in 1945 was revised by Balanchine so that the performers wore practice leotards, with short chiffon skirts (see The George Balanchine Foundation 2007). At that time, the costumes were all black; they were changed into the ultimate (nearly) all-white appearance in Balanchine's resident NYCB in 1952

4. The costume credits are complicated in this work. The first design (Toronto 1991 premiere) featured leotards by Forsythe, with the 'Colombe dress' by Issey Miyake, as a stage prop. Forsythe's design was later modified a couple of times, and some companies still perform in his costumes (grey
In western theatre dance, stage costumes historically have complex ties with practice clothing, as explained in the lexicon overview by Susan Au (1998). In ballet too, as discussed by dance historian Lilian Moore (1960), related resonances may be traced throughout history. One contemporary costume type that originates from rehearsal wear is leotard or body suit, ${ }^{1}$ whose popularity was on the rise during the middle of the twentieth century both offstage and onstage, and in modern dance and ballet alike. Moore in the article 'Practice clothes then and now' praises leotard as the 'ideal practice dress' (1960: 124).

Never before have practice clothes incorporated such beauty and the simplicity of design with such comfort and practicality. The trim contour of the perfect-fitting leotard, revealing the play of every muscle to the critical eye of the teacher or choreographer, has actually influenced the development of dance technique of our time, helping the dancer to achieve a new long line, a new breadth of movement.

(1960: 118)

Moore's point is of interest as it implies the influence of this garment over the evolution of technique, since its clever design motivated the refinement of dancer's movement and line. Leotard also impacted upon various aspects of the dancer's work: it promoted the feeling of comfort and increased the visibility of bodily expressiveness, while the simplicity of design facilitated an easier feedback in the studio. Moore's points suggest likely reasons why this attire, which originated outside dance, for its functionality became popular in ballet culture. The emergence of leotard as a stage costume, however, brought out different aspects. The dancers who embraced it as workwear in the studio were challenged by its use onstage. This complexity of the relationship between the dancer and the leotard is exemplified in the anecdotal accounts surrounding the earliest undecorated body tights as ballet costumes in the West, the quixotic leotards that painter Pavel Tchelitchew designed for Diaghliev's Ballets Russes' Ode (1928), choreographed by Leonide Massine. A performer in the work, ballerina Alexandra Danilova, spoke about the unsettling feeling produced by this costume type. According to her recollection, because this was their first time to appear in seemingly undecorated body suits, many performers felt 'so naked' that they wore dressing gowns over the costumes 'until the moment before the curtain went up' (1986: 175). This feeling was contrasted by the dancers' understanding of the aesthetic ideas behind such costumes. Danilova, who was also a close early collaborator to choreographer George Balanchine, expressed an appreciation for the artistic rationale behind his use of this costume type:

... [C] ]ostumes were part of choreography - we would run and our skirts would flow behind us, giving our running an ethereal quality. In a leotard, that same running looks different, often, a leotard obliges you to move differently.

(Danilova 1986: 174)

Danilova's example suggests a layered relationship between leotards, both as rehearsal wear and costumes, and the dancer who may embody them with ambivalent feelings. This article looks in detail into this complex relationship, with its affinities, attractions and tensions. The article's framework thus leads me to discuss 'leotard' as a type, rather than to attempt to analyse the myriad 
of variations in fabric, design and cut, even though I address those aspects where relevant for the correlation between the design and choreographic, or performing concerns. Overall, I aim to show the significance of this costume type for the development of choreography and performance. Such a closer look unveils a discrete lineage of contemporary ballet, the one in which the costume type holds a significant role.

In this sense it is important to note the moment of an artistic shift that opened the way for the popularity of practice-clothes aesthetic in ballet. Although not one of the earliest examples of such an aesthetic (not even in his repertoire), the moment of Balanchine's stark revision of previously elaborately designed 1946 ballet Four Temperaments may be read as the point of Foucauldian rupture in ballet history. The original work, which included the flamboyant sets and costumes by Kurt Seligmann, was 'stripped' by Balanchine to monochromatic practice dress, similar to the costumes ballet students wear in the school and in rehearsals. The new version in 1951, titled The Four Temperaments, was performed on a bare stage, in front of a coloured cyclorama. This was an important anti-costume intervention that asserted and secured the practice-clothes leotards as a powerful ideological alternative to the narrative, costumed and ornately designed ballet tradition. Taking out of the decorative elements, thus emphasizing the dance movement as the primary concern of choreography, also deterred the viewer from the conventions of ballet tradition, such as references to characters and libretti.

It is important to clarify that the practice-clothes aesthetic is just one of leotard ballet sub-lineages, as the use of this costume greatly diversified during the past century. In 1973, Leo Kersley and Janet Sinclair in the third edition of their ballet dictionary, acknowledged the broad variations in the design and style of this costume. Their 'leotard' entry explains it as a 'tightly fitting garment covering the body from wrists to ankle', but a great heterogeneity is also noted:

$[\mathrm{M}]$ any varieties are used today, both in the practice room - where it has the double advantage of at once keeping the limbs warm and revealing every line of the body - and on the stage, either without ornamentation for many 'practice dress' ballets in vogue today or decorated as in Sidney Nolan's costumes for The Rite of Spring (MacMillan).

(Kersley and Sinclair 1973: 78)

This description of ballet leotards reminds that many versions emerged, from unembellished rehearsal wear and the school uniform appearance on one end of the spectrum to the highly ornate, whimsical tricots on the opposite end. The latter decorated body tights that indeed appeared on the ballet stage earlier than the practice-clothes aesthetic, as seen for instance in Leon Bakst's Ballets Russes costumes for Nijinsky in Le spectre de la rose (1911) and L'àpres midi d'un faune (1912), and in many works onward. A separate lineage may be traced in this sense, and that one has far fewer direct references to the practice dress and backstage culture.

This article focuses solely on the 'practice-clothes' leotards that arguably communicate new meanings about ballet as a dance genre and sociocultural practice, as seen in the paradigmatic example of The Four Temperaments. American dance writer Robert Greskovic, for instance, asserts that spare aesthetic of these 'black and white' ballets represents the 'twentieth-century counterpart to nineteenth-century ballet blanc ${ }^{2}$ tradition' (1998: 200-01). Whether we may long-sleeved leotards and grey tights, as on the photographs in the text). More recently, the design is standardized and leotards redesigned by former Dresden Semper Oper ballerina Yumiko Takeshima (same grey-shade female leotards are sleeveless, with high collar and a large oval cutout on the back, see Dresden Semper Oper Ballett or Boston Ballet versions). Since 1991 Ballett Frankfurt production, the Miyake dress functions as an additional (non-leotard) costume for a soloist ('Kate [Strong's]' solo). The collaboration between Miyake and Forsythe famously foregrounded Pleats Please concept launched in 1993, featuring innovative synthetic polyester fabrics pleated in complex combinations of origami-style foldings (see 'The Concepts and Works of Issey Miyake', http:// mds.isseymiyake. com/im/en/work/) For a period, in Ballett Frankfurt the female leotards in the second detail were replaced by the Pleats Please Miyake short tunics, as seen on The Loss of Small Detail 2002 recording in The Loss Project archive (LABAN London). 
agree with Greskovic or not, his position suggests that these ballets form a discrete ballet genre. Several vernacular terms emerged in the dance discourse: 'practice-clothes ballet', 'leotard ballet' or 'black and white ballet'. These are often employed interchangeably, although the latter appears more specifically in the discussions of specific repertoires (including Balanchine, Jerome Robbins or Jiří Kylián). While each is limiting, these umbrella terms are also interesting, as together they underline the importance of the costume type for the denotation of the aesthetic. Their common features include seemingly undecorated, monochrome or solid colour leotards, in many variations, including coveredleg versions (the unitards), or sometimes particularly for men, tight-fitting tops and tights; the women wear pointe shoes and men soft ballet slippers, although later sometimes the dancers perform in socks (as in some ballets by William Forsythe). The stage design is often minimal or omitted, with the lighting effects or sometimes a simple cyclorama (as in The Four Temperaments) functioning as the key decor. As mentioned, the frequent lack of libretti makes the conceptual or referential associations subdued.

Visually and conceptually, this genre seems to exclude more than it includes. The spectator's attention is directed towards the performer's body form in motion, and towards the relationships that evolve onstage (dancers, music, space). For the performers, the conceptualization of a role involves a fluid connection to the character and plot, all of which possibly make such works more opened for interpretation. This is why this aesthetic has important implications for the development of twentieth- and twenty-first century ballet as a tradition, as it offers alternative ideas about ballet as a cultural practice, as will be discussed further. The place of the costume is critical in each of the aspects, and the following sections aim to look further into several of them.

\section{THE REVEALED DANCER}

Without trying to outline the history of leotards as a stage costume, it is interesting to note that one of its earliest appearances is outside the dance: Iphigénie en Aulide was a production of the Paris Opéra Comique (1908) where, as pointed out by dance historian Jane Pritchard, the corps de ballet 'wore dark all-over body tights to form sculptural groups' (Pritchard 2010). In dance, as Moore (1960) noted, Doris Humphrey included practice-style leotards in her stage productions in 1923-1924, and in ballet specifically, the early precedent was aforementioned Massine's Ode (1928). Leotards thus gained a place within the twentieth-century history early, yet close to a century later they still bring anxieties for some dancers. According to Xiao Nan Yu, today's prima ballerina in the National Ballet of Canada, it is implied that professional dancers should be accustomed to this aesthetic and overcome 'the barrier' of self-consciousness. Nevertheless, as Yu suggests, in a revealing costume it is inevitable that the performer's stage presence 'consists absolutely' of their figure, which makes them 'subconsciously ... more aware of the body' during the performance (Yu 2009). A related point was made by the Royal Ballet principal dancer Nehemiah Kish who suggested that for some dancers the feeling of being exposed might be extended to a certain sensitivity about the body line in reference to the technique: in a body suit 'there is nothing to hide behind' (Kish 2011).

It is also interesting to note that a level of dis/comfort is in some measure relative to the dancers' backgrounds and ballet cultures. In Balanchine's New York City Ballet (NYCB) black and white dances are performed regularly 
nearly from the company creation in the mid-twentieth century until today. The later generations of Balanchine's dancers (for instance, those who performed in the late 1970s and 1980s) 'grew up' in leotards and therefore many do not feel as self-conscious: performing in a leotard is a significant part of their tradition. A dancer schooled in the company's associated School of American Ballet and subsequently the NYCB ballerina between 1970s and 1990s, Maria Calegari explained that performing in a leotard did not make her nervous: 'We just grew up seeing the aesthetic and understanding the philosophy of it, where the movement was primary' (Calegari 2011). Calegari's point relates to Danilova's understanding of the aesthetic rationale behind the use of costume, and thus shows that a type of training makes the dancer used to performing in a leotard, and represents a way of overcoming the feeling of unease.

For some dancers the sense of freedom or exposure may be dependent on slight differences in the type of the body suit. Former ballerina in the Royal Ballet, Deborah Bull felt that the key was in the finer details of the design: a leotard and tights were more comfortable than a unitard that left 'nothing to tweak or hide behind'. With leotards some elements could be adjusted through tailoring to make the dancer feel more comfortable: in Forsythe's Steptext (1985) there was a possibility of a higher- or lower-cut leotard around the thighs; in Balanchine's Agon there was a belt over it, to pull up or down. But, it was not as possible to customize the unitard, and therefore one could feel 'essentially naked, but with colour' (Bull 2011). Bull, however, suggests that the feelings of confidence or self-consciousness usually 'fluctuate over the course of the dancer's career', while only rare performers may have a constant comfort level with their body shape in this costume. According to Bull, the main power of leotard is in the possibility of 'unconsciously setting up' an 'internal feeling which colours the way one steps out onto the stage'. As such, the costume may have implications for the dancer's interpretation: 'Depending on how you feel about your body', this type of costume may 'set one up to start the performance with a sense of vulnerability, or from a stance of power' (Bull 2011).

These points about the subtle details that bring significant changes are important as this is true both for the dancer's approach and for the aesthetic identity of the choreographic work. Costume designer Holly Hynes who created many leotard costumes, and worked as a costume consultant for the New York City Ballet, points out that any existing detail is more exposed in the spare design, than in the elaborately detailed costumes (Hynes 2010). This often poses great challenges in restagings and reconstructions. For example, in the case of ballet Polyphonia (2000) choreographed by Christopher Wheeldon, Hynes as the designer worked on achieving the particular shade of purple leotards, because this was important part of the choreographic exploration; a slim shiny belt worn by female dancers over the leotards was a significant accent too (Hynes 2010). Subsequently, Marjory Fielding, the Wardrobe Supervisor in the National Ballet of Canada, who worked with Hynes to remount Polyphonia, found difficulties identifying the belt that would create the same accent for the Canadian restaging: the exact sheen and thickness were difficult to replicate. In other ballets there are similarly important details: in the case of Forsythe's the second detail (1991) one of the greatest challenges for Fielding is to achieve consistency of the particular grey shade of the female costume across restagings, as the shade and sheer texture of grey tights are difficult to maintain across revivals of the ballet (Fielding 2010). 
Any change in sparely designed leotard costumes, therefore, may have a significant impact upon the identity of the work. I would extend this point to include performance, which is a question provoked by Hynes's and Bull's comments in conjunction: because leotard ballets are visually spare, any subtle changes in the embodiment of choreography or difference in the style may stand out much more clearly. This may be interesting and highlight the dancer's agency, but also may bring an undesired impact upon the choreographic text. The correlation between the aesthetic concerns and performance thus reveals a fine balance of small details that is exposed through the costume, whose design is often largely concealed.

\section{THE COSTUME STYLE AND ITS AESTHETIC ROLE IN THE EMERGENCE OF A SUB-GENRE}

In addition to the dancer's inner feeling about performing in a leotard, previous discussion shows how the relationship with this costume type is also dependent upon an understanding of the choreographic intention. The label 'black and white ballet' is particularly interesting in this sense. Some of these works, including Concerto Barocco ${ }^{3}$ and The Four Temperaments (1951), are among the earliest practice-clothes ballets, which still remain in the international repertory. As with The Four Temperaments, usually the look of these ballets evolved from more decorative design into a monochromatic appearance. As explained in the online catalogue of The George Balanchine Foundation (2007), this ballet is also a reminder that not all Balanchine's black and white ballets are visually contrasting. Some are mostly in one tone (all black, or all white), and some also include colour accents, as in the case of 1972 Stravinsky Festival works Symphony in Three Movements and Duo Concertant. Overall, the aesthetic in all these ballets produces an effect that suggests an alliance with modernism. Dance historian Lynn Garafola sees the monochrome visual appearance as a reflection of modernity, a metaphor for post-war New York. These ballets, she suggests, exude anguish and pronounced sexuality, and Balanchine in them 'had bared the very bones of his choreography' (Garafola 2005: 243-44).

The aesthetic also accentuates choreographic explorations of movement as the medium and material of dance as an art form, as these ballets may be seen as integral to his artistic interpretation of musical scores. Dance historian and choreo-musicologist Stephanie Jordan (2007: 163-64) points out that the aesthetic of black and white reached its peak during Balanchine's famous experimentations with highly formal 'twelve-note' musical scores in the late 1950s - early 1960s, including Agon (1957), Episodes (1959), and Movements for Piano and Orchestra (1963). Jordan analyses the structural interplays between movement and music, which fully came to the fore in these works. It could be added that the contrasting costumes amplify this effect through graphic contrasts that support the choreographic visualization of musical structures. Throughout the 'Pas de deux' in Agon a viewer may observe checkered visual images emerge, as the costumes work in tandem with the kinetic phrases of surprising partnering. These contrasting displays may remind us that Stravinsky engaged into musical atonal structural games within the score. The photographs by Martha Swope (published on the cover of Banes 1998) show dancers Diana Adams and Arthur Mitchell forming visual contrasts with their costumed bodies: the woman in a deep penchée arabesque over the kneeling man's shoulder, with contrasting tops (Adams in black, Mitchell in white) pressing against one another; there is the additional contrast of legs 
in diverging colour tights, in the opposite directions in the space. Of course, in the original performance there was also an all-important interracial casting, which obviously brought out possible deeper political readings. For the purpose of the aesthetic argument here, it is important to note the reading by the dancer, Mitchell, who felt that Balanchine's casting in the pas de deux certainly functioned as another visual layer in the choreographic structure:

There was a definite use of the skin tones in terms of Diana being so pale and me being so dark, so that even the placing of the hands or the arms provided a color structure integrated into the choreographic one.

(Mitchell in Mason 1991: 395)

The plotless dance too may be seen as an intention to push the movementmusic interplay to the forefront. The use of a simple, practice leotard as a costume thus enhanced the choreographic idea, and helped the dancer's conceptual understanding of the plotless work and own position as an agent of performance, in the aesthetic sense.

\section{LEOTARDS AND THE VERNACULAR: PROMOTING THE LEGIBILITY OF DANCE}

The emergence of tight-fitting leotard in dance owes to several historical precedents, all of which in some measure related to the idea of revealing the movement and freeing the body. The bold invention of this costume in the 1850s circus culture is usually emphasized, as this is where the body suit idea was formulated to enhance the display and facility of movement - leotard is famously named after French trapeze artist Jules Léotard. One of the theatre examples comes from mime. Theatre historian Edward Nye describes experimentations of the eighteenth-century mime choreographer Étienne Decroux, who 'sometimes performed in a body stocking or little more than a loin cloth, covering the face with an expressionless mask or even a more rudimentary stocking'. This strand of postural, 'corporeal mime', in contrast with the gestural mime highlighted the 'untapped expressive potentials of the whole body' (Nye 2011: 87). The emergence of the twentieth-century leotard is indebted to swimwear developments, particularly Annette Kellerman's bold invention of one-piece swimming costume from the early 1900s (discussed in Hargreaves 1994: 136). Bathing suit as a ballet costume was designed by Coco Chanel for the production of Bronislava Nijinska's Le train bleu (1924) in the Ballets Russes. Effectively those are some of the earliest sparely designed body suits created as snuggling, machine knitwear.

Plenty might be said about the historical significance of the knit technologies for the development of costume innovations, and a separate study could be made about the impact on the fabric over the certain choreographic and performing styles. For the present discussion it is important that the knitted leotard helped the dancer move with an expanded kinaesphere, which in turn may be associated with the developments of technique and style (a wider range of movement, the tendency towards the expanded limb extensions and elevations also begins to develop throughout this time). Balanchine's shedding of the elaborate costumes in The Four Temperaments, and the far lighter replacement, leotards, changed the dancer's feeling of movement. Todd Bolender, the original soloist in the 'Phlegmatic' variation from 1946 Four Temperaments, felt relieved when Balanchine stripped the original Seligmann's 
novel designs. Bolender originally wore a heavy, woolen costume, which soaked with perspiration quickly in performance; the dancer also wore a soft brimmed mushroom-shaped hat, which obstructed his view of the stage. The dressed-down version delighted the dancer: 'I felt that I could soar more', he expressed, even though the role does not require much virtuosity or high jumps (Bolender 2005). Although we have no film records to follow this dancer's movement style through the costume change, Bolender's statement indicates how the change in costume impacted on the dancer's phenomenal experience of the choreography, which may have provoked both the modifications of performing styles, as well as the conceptual interpretation of the dance material.

This emphasis on the facility of movement reveals why leotard, although exposing, was also a medium, which put the performer at ease. Furthermore, the leotard reminds of the comfortable place - the ballet studio. Deborah Bull, for instance, felt this effect while preparing an important soloist role. Performing the 'First pas de trois' from Agon early in her career was a comfortable step in her artistic development, as the role felt as a 'very good first step into solo work': while 'most dancers progress through other roles ... for example, The Sleeping Beauty fairies' solos', Agon trio 'felt very close to classroom technique, and the costumes were similar to classroom clothing' (Bull 2011).

These ballets also may make the spectator feel privy to the creative process, the backstage work. For some dancers leotards are comfortable as they soften the transition between the rehearsal and performance. Former principal dancer in the Australian Ballet and the NBOC Geon Van der Wyst suggests that practice costumes dissolve binaries between the studio and the stage: 'everything you felt there [backstage], you feel exactly the same here [in performance]' (Van der Wyst 2010).

When you perform in practice clothes, the transition from rehearsal to performance is almost seamless, because you really don't rehearse in your performance costume very often. So, having that level of comfort gives your interpretation the ease of transition. This is the case when, really, there aren't extra layers to have to get used to between the two: a headdress, a thicker costume, or some other prop.

(Van der Wyst 2010)

However, tight-fitting leotards are not always used as practice clothes by today's dancers. While this clothing type is still a uniform in professional ballet schools, after the dancers join a company, practice wear is individualized. Therefore, as Van der Wyst notes, the level of freedom in a leotard may be 'contingent upon' what the dancer customarily wears in rehearsals. If dancers rehearse in 'many clothing layers' they may feel more exposed onstage, since they are no longer accustomed to embodying movement in 'only one thin layer of lycra or cotton of which a leotard can be made' (Van der Wyst 2010).

The vernacular aspects of leotard costumes are particularly interesting to follow as the look evolved in the recent years. Nowadays the practice-clothes aesthetic involves the use of less formal-looking studio garments, which occurred in postmodern dance widely. In ballet too, Forsythe's 1980s and 1990s 'ballet-ballets' (to borrow this choreographer's term, see Forsythe in Siegmund 1999; Tusa 1999) are related examples. Forsythe's own designs for Steptext (1985) or Stephen Galloway's designs for his workwithinwork (1998) include not only leotards but also T-shirts, cropped tights, shorts and tank tops, all of which 
represent a reformed 'leotard' aesthetic, interpreted through contemporary street wear. The effect of Galloway's approach in workwithinwork, for example, is a leotard-style remixed - a subdued design, as if the dancers walk out on the stage in their own personal clothing, and perform as themselves, not as imagined characters. The style of rehearsal-wear also reflected the culture of its company, Ballett Frankfurt, in which dancers often wore sports garments and items of 'pedestrian' clothing in the studio - track suits, loose sportswear and T-shirts. The company dancer at the time, Galloway as a costume designer was inspired by the everyday look from the company studio, but has applied a sensitive design edit to streamline it, thus integrating various elements. Ballett Frankfurt dancers at times wore socks over dance footwear and running shoes, and Galloway combined this look with some of his designs. In certain works, such as One Flat Thing Reproduced (2000) he incorporated found objects (retail clothing garments). Constantly revising the look, particularly in the restagings for the international companies, Galloway devised a kind of a 'live remix' in practice-clothes aesthetic (Galloway 2011). This effect, as summarized by former Ballett Frankfurt dancer and frequent stager of ballet-ballets Jill Johnson, was powerful, subtle and naturalistic at once, 'the colours occur in a way they might in nature, a definite and dynamic cohesion, but not apparently organized' (Johnson 2010). It is possible to understand Galloway's approach to costuming as a parallel to Forsythe's choreographic ideas in which movement material was

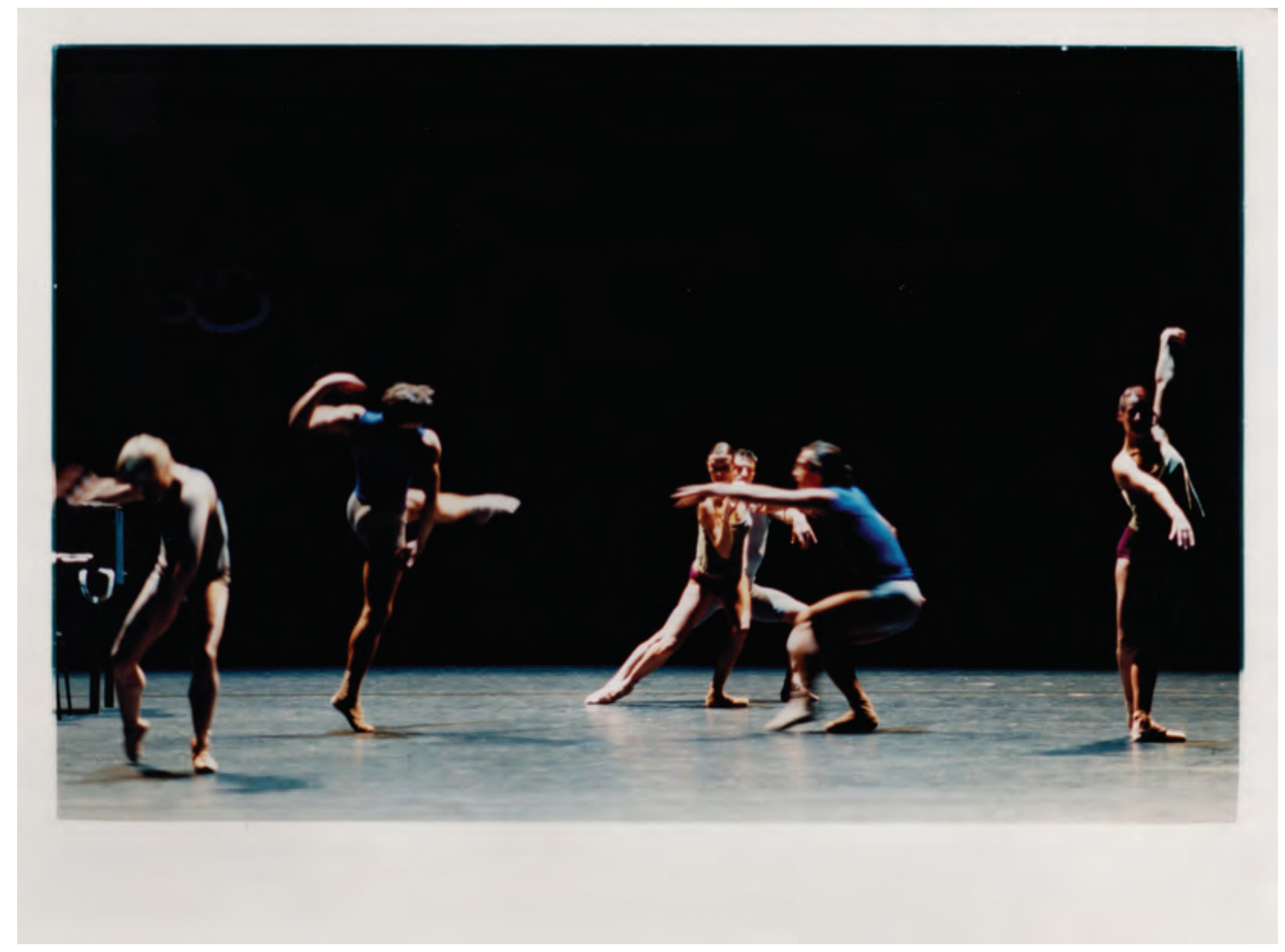

Figure 1: Ballett Frankfurt in performance of William Forsythe's workwithinwork. Costumes by Stephen Galloway. Photo: Dominik Mentzos. Image with courtesy of The Forsythe Company and Dominik Mentzos. 
often developed through a kind of 'a circular mix' (Caspersen 2014). Forsythe offered ideas, motion material, text or tasks, and the dancers responded by expanding on what was offered or creating subcategories of research or new ideas in counterpoint, all of which would be integrated, and process repeated multiple times. Galloway's costume aesthetic thus developed in synergy with the choreographic approach, and thus is both an homage and opening out of the tradition of practice clothing onstage, now updated as an end-ofthe-century image.

\section{LEOTARD AS A NON-COSTUME: TRANSPARENCY, PERSONAL AND CULTURAL DISCLOSURES}

It is clear that Balanchine's aesthetic interventions such as The Four Temperaments, and Forsythe's carefully designed vernacular practice-clothes style, had to expand the freedom of artistic expression for the choreographers, costume designers (such as Galloway) and for dancers. But it is still important to address the notion of freedom in reference to what was suggested by Van der Wyst and Danilova: for dancers there may be a difference between the use of leotards in the semi/private (the studio) and public (the performance). Moore, for instance, observes cultural differences that can be spotted on the illustrations of 1820 ballet technique manual by ballet master Carlo Blazis: while the French version depicted [male] movement demonstrators in breeches and topless, the English edition shows the dancer performing the same exercises, now modestly covered (Moore 1960: 119).

In sociocultural sense, the twentieth century stripped-down appearance in ballet may be linked to the era's emergence of ideological statements, sometimes celebrating an eloquent and aesthetic body form. The freedom of movement transgressed into nude dances in the 'body culture' in pre-war Germany (Toepfer 1997) as well as in the 'natural body' experiments elsewhere in Europe around 1930s (Hargreaves 1994). For ballet, particularly interesting are body celebrations in the post-revolutionary Russia. As explained by dance historian Elizabeth Souritz (1990: 182), in the early 1920s, a number of avant-garde artists and theorists in the young Soviet culture propagated the aesthetic celebrations of the bare body, as a symbol of beauty in harmony with nature and liberated from religious dogma. Ballet choreographer Kassian Goleizovsky (who according to many historians influenced Balanchine's earliest choreographic ideas) in the 1920s choreographed the ballet The Faun for the Moscow Chamber Ballet. Art historian Nicoletta Misler (2000: 99) finds that this ballet represented 'the manifestation of the naked body onstage'. The dancers performed in revealing costumes by Boris Erdeman, dressed in minimally required clothing (the simple briefs and textile bands), so that the costumes functioned as an extension of the dance movement. Misler (1991: 162) also notes one of Goleizovsky's contemporaries, choreographer Lev Lukin who was inspired by the design of the simple prozodezhda (a type of work uniform) for his revealing black and silver colour-blocked briefs and tops, which aimed to break the symmetry of the body. Lukin's experimentations became even more radical when he collaborated with designer Sergei Yutkevich who conceptualized 'non-costumes' (Yutkevich cited in Misler 1991: 162), featuring dancers in the nude, with bodies painted in red, green and black paint.

Balanchine's monochrome ballets may be seen as a less radical, but for ballet institutions of the time, sufficiently radical 'non-costume' aesthetic. 
They are described by dance writer Marcia Siegel (1985: 228) as 'transparent', as she sees them as a medium for showcasing the movement 'without intermediaries'. Francis Sparshott's in his analysis of nudity in the theatre seems to concur, arguing that monochromatic, close-fitting costume reveals more than a bare body (1995: 306). The legibility is increased when a simple cloth is fitted over the dancer's body, while the naked 'flexible torso with four pivoting limbs, plus head and neck...risks destroying this articulation' (Sparshott 1995: 304). In this sense, he singles out Balanchine's 'reduction of costume to a close-fitting sheath of black and white', which 'made the dancing body entirely visible without unseemly direction of the attention, effected in its approximation to nakedness a sort of austerity of the flesh, making of the body a pure agency of dance' (1995: 304). Furthermore, the stripped-down nude appearances in the theatre Sparshott sees as an ideological element, which may be linked to the earlier discussion of The Four Temperaments as an anti-costume intervention. Sparshott explains that costume with its ornamentations often supports the narrative, but also imposes 'distracting social connotations' (1995: 306). Therefore, if the costume enhances signifiers of social hierarchy, the nudity on the stage disrupts them. Sparshott's point may be extended to practice-clothes leotards, which are often undecorated and uniform as in the ballet class: this costume type in some measure suspends

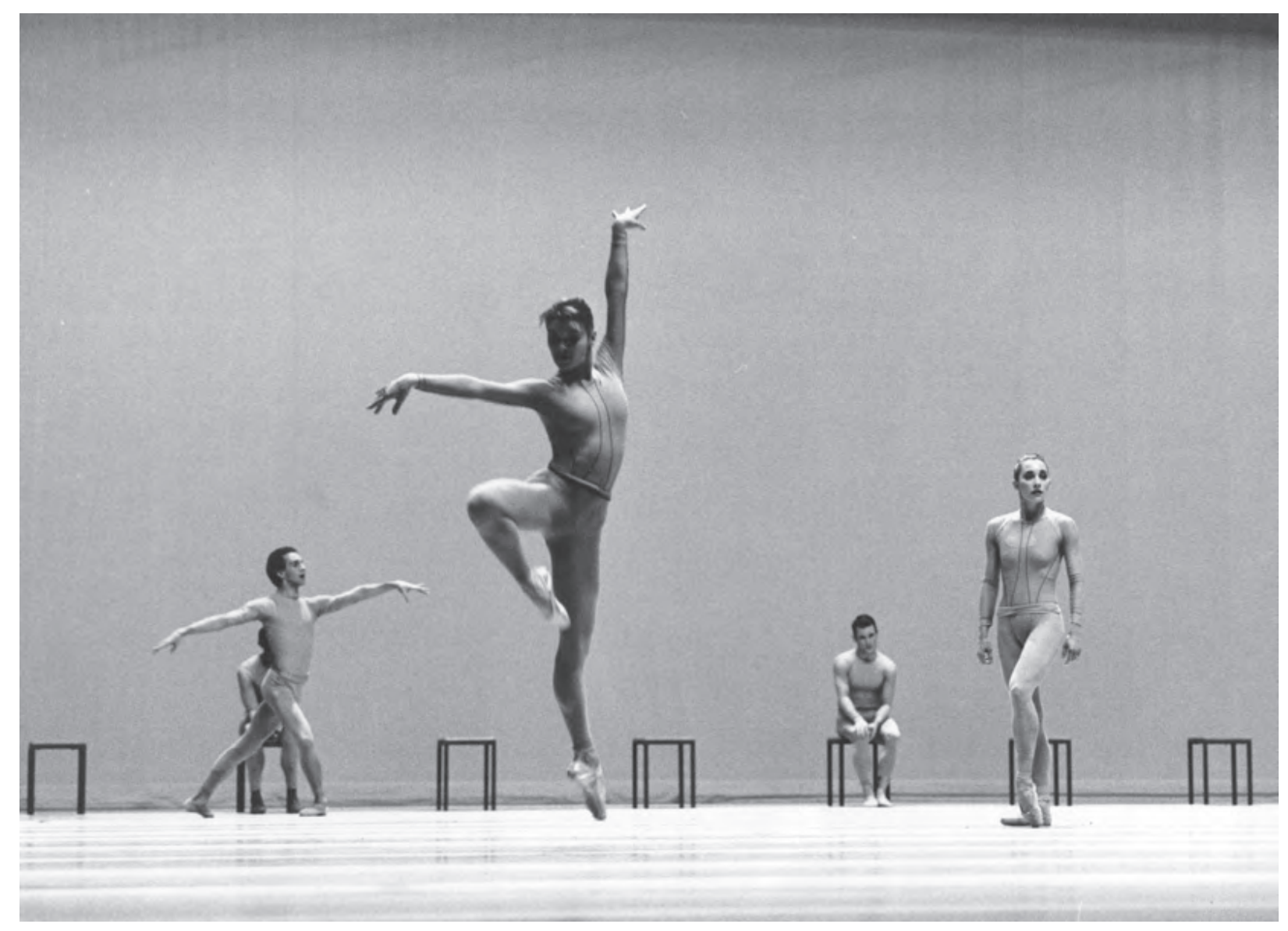

Figure 2: Agnès Noltenius and Ballet Frankfurt dancers in the second detail. Choreography and costumes by William Forsythe. Photo by Dominik Mentzos. Image with courtesy of The Forsythe Company and Dominik Mentzos. 


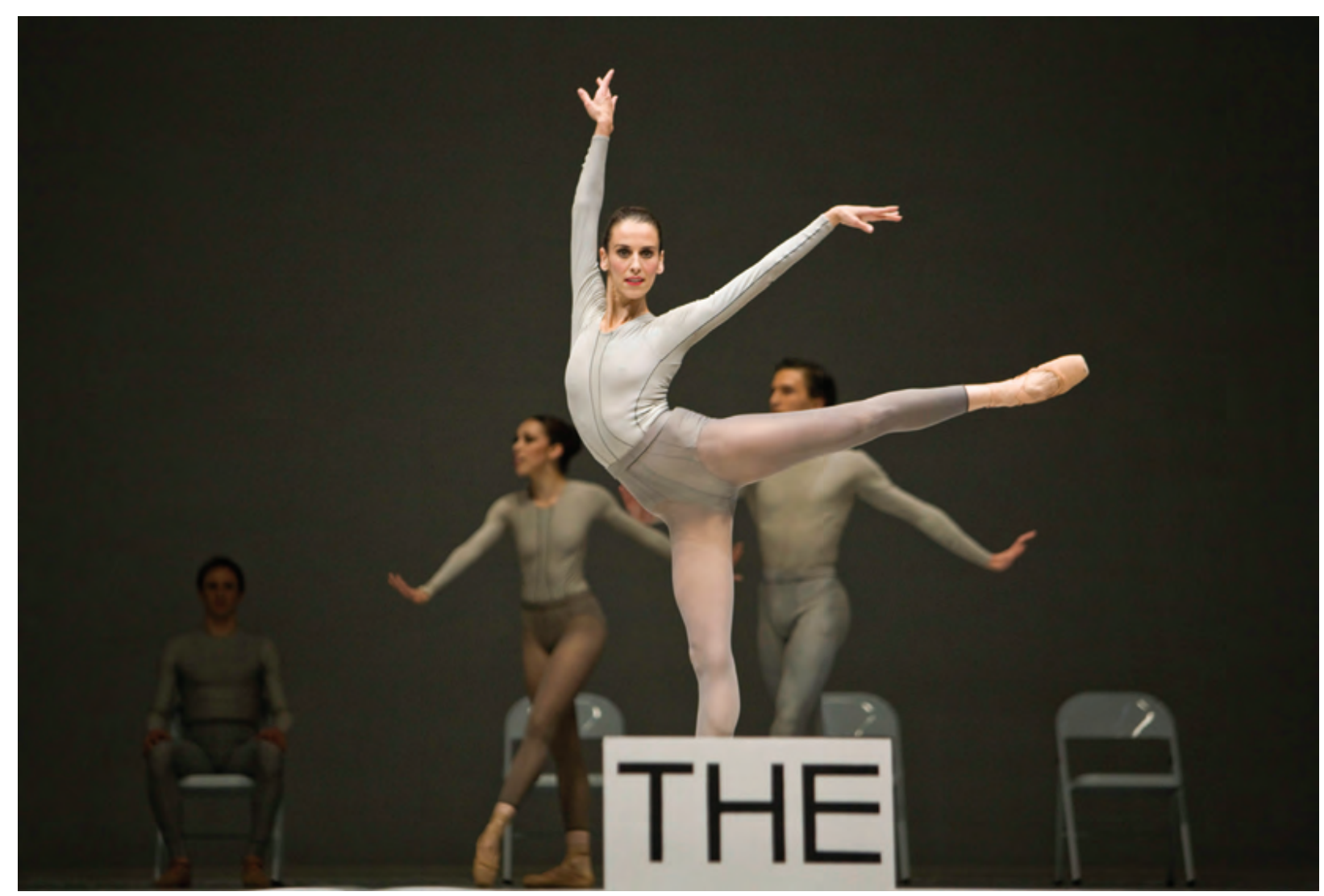

Figure 3: Sonia Rodriguez with Artists of the National Ballet of Canada in the second detail, in costumes by William Forsythe. Photo by Cylla von Tiedemann. Image with courtesy of The National Ballet of Canada.

social divisions, which are traditional to ballet culture and institutions. The ballet emploi, or the strong distinction between the roles, performance tasks and dancers' ranks (principals, soloists and ensemble) is thus disrupted by the uniformed look of leotard ballets, where the implied hierarchy is not necessarily recognizable.

The effect of dissolved hierarchy is particularly strong in Forsythe's balletballets, which offer interesting challenges for repertory company dancers. For example, ensemble work the second detail (1991) features choreographic organization of dancers onstage that reflects the non-hierarchical culture of his resident Ballett Frankfurt (the company during 1984-2004). The ensemble structure features multiple groups of dancers, performing in counterpoint. The casting frequently mixes the ensemble with soloists and principals. At different moments, various dancers have brief solos and chances to stand out. Overall, there is a strong impression of movement research in the communal space where everyone seems equal. This impression of cooperation is underscored by the uniformed look of dancers in grey leotards, designed by Forsythe in collaboration with the National Ballet of Canada costume department. ${ }^{4}$

Although the second detail was initially created for the National Ballet of Canada, it was further developed into a two-part, full-evening The Loss of Small Detail (1991) in the Ballett Frankfurt production. As explained by Johnson, in Frankfurt in general the improvisational base of the work often required a tight communal exchange through verbal and embodied eloquence in the communication between the dancers. This approach in turn 


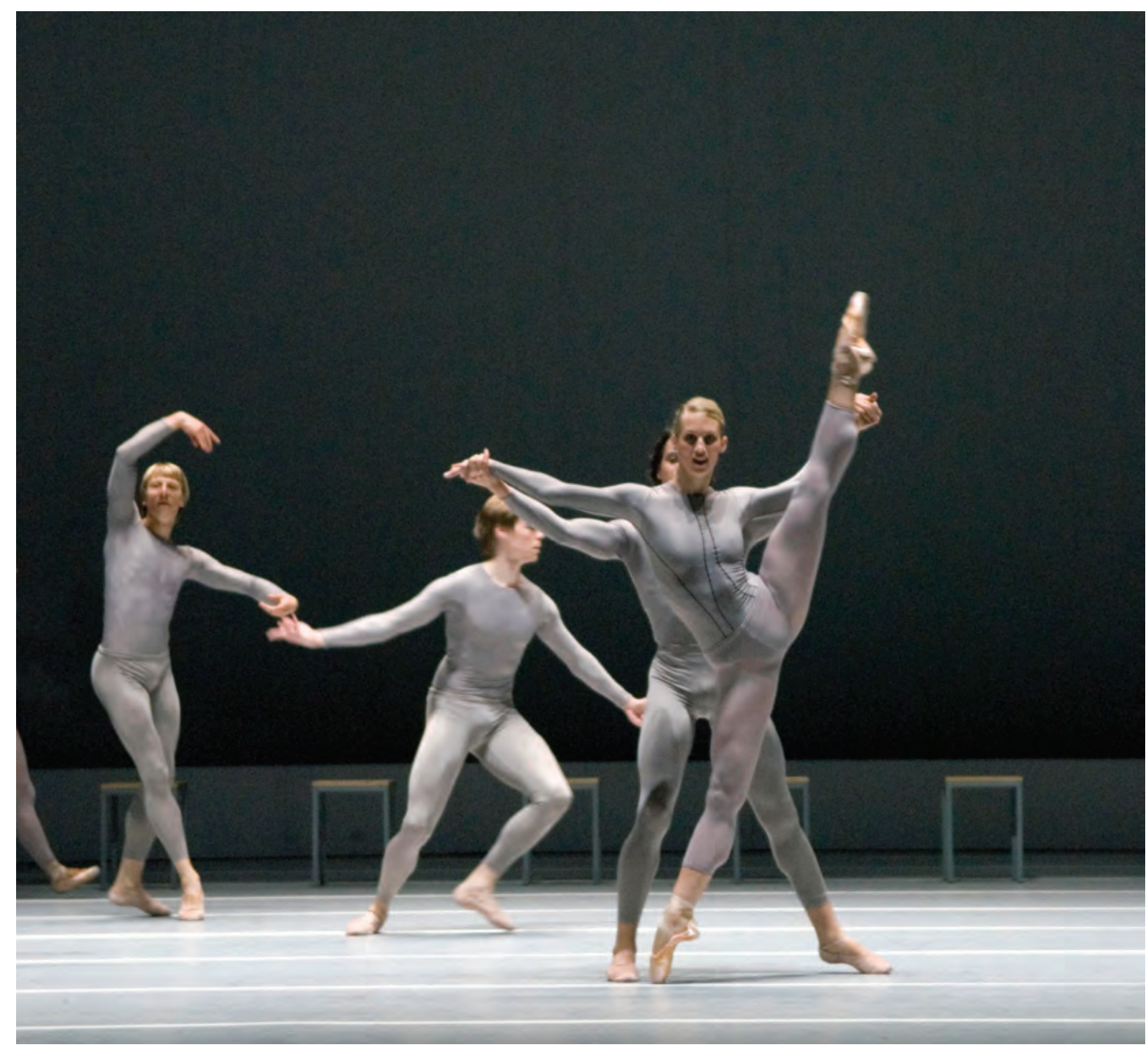

Figure 4: Hayley Forskitt and the artists of The Norwegian National Ballet, the second detail. Costumes and choreography by William Forsythe. Photo by Erik Berg. Image with courtesy of The Norwegian National Ballet and Erik Berg.

helped nurture a sense of collective exploration, where members customarily taught passages of their roles to each other (Johnson 2008). When performed in the repertory companies, only the revised first part - the second detail - is performed.

As some dancers report, this work produces interesting challenges for a repertory ballet company culture. One of the cast members in the 2008 National Ballet of Canada production, Zdenek Konvalina, as a principal dancer is often a featured dancer onstage. Konvalina explained that the second detail to him represented a particular 'double challenge': he felt that it was important to remain an equal to everyone onstage, yet to use the chances to show off the personal qualities - to 'stand out from the crowd' (Konvalina 2009). The balancing act experienced by Konvalina reveals how the choreography, supported by the costume, enhanced the subversions of hierarchy, thus questioning and repositioning the individual, institutional and cultural politics. It 
also signalled how a choreographic idea through the use of practice-clothes leotards may help shift traditional attitudes in ballet.

Individual attitudes of dancers so far in various examples revealed particular dancers' positions towards performing in a leotard. In reference to Sparshott's remark about 'distracting' connotations found in costuming, it is interesting to note the dancer's perspective. Merrill Ashley, New York City Ballet ballerina from the Balanchine era, found that leotards particularly enhanced a conceptual breadth and individuality: the dancer may be 'much more of a blank slate - you don't have to be, or feel, frilly or pink or green, or anything ... but yourself'. The dance becomes about the elements present, such as the music and the dynamics of movement: 'And then you interpret all that in a way that seems natural to you, as an individual' (Ashley 2011). In this sense, a leotard may promote the feeling of 'being a dancer', rather than a character, a persona. A related point is expressed by former prima ballerina from the National Ballet of Canada, Martine Lamy, for whom the style of costume was one of the significant conceptual elements when developing a role, as its combination with the setting affected how she thought of herself in the dance. As soon as she had 'a tutu and a tiara on' Lamy felt like someone else:

In such roles, I would have to have a persona because I would feel in a way more precious than I've ever been in my life. So, it's just automatic - I would have to elevate my state of mind to a place where I'm not normally.

(Lamy 2011)

In contrast with the elaborate costumes that made her act as a character, the simple leotard designs for Lamy promoted 'feeling like herself' in performance. The lack of decorations and props helped her relate to her own personal life in a role (Lamy 2011). It is interesting to read Lamy's account in conjunction with another observation offered by Bull: the simplicity of dressed-down costumes promotes certain 'honesty' in performance. The absence of theatrical elements and the details of costuming, Bull suggests, reveals the 'personality' of the performer, as 'people's values and beliefs' stand out more: a daring dancer reveals herself, just as a timid personality or a meticulous and exacting approach to performance stands out more clearly. 'You do get a sense of people's characters, actually...their quirkiness, or where the boundaries lie, how they feel about things' (Bull 2011). Although this enhanced view may be possible in other works and roles too, it is important to recognize the conceptual freedom and amplified sense of self the dancers found in the practiceclothes roles.

This article shows the rehearsal-style leotard as a costume type and one of the key elements for understanding of the seminal twentieth- and twentyfirst century ballet genre. The leotard holds a central place for the denotation of the practice-clothes genre. It supported the development of ballet technique, choreography and performance. When it emerged as a costume in the mid-twentieth century, it aligned ballet with modernist explorations, as in Balanchine's black and white works. The relationship between the costume style and the performers is complex. The understated aesthetic enabled new conceptual and embodied freedoms, although at the same time the costume was [sometimes too] exposing. As its appearance evolved, the reformed, yet still concealed designs at the turn of the twenty-first century enabled certain shifts of cultural attitudes, and opened way for postmodernist vernacular 
explorations in ballet, as seen in Forsythe's works where the costume methodologies fully developed in synergy with the choreographic ideas. All the discussions show that the analysis of the leotard as a type of dance costume uncovers a wealth of information about the relationship between the visual design, the choreography and performance. Ballet's sociocultural context is

also explained when this costume is considered as one of the key aspects of the work's aesthetic. The costume supported certain subversive attitudes, as an anti-establishment, anti-costume or non-costume stance. In conjunction with other performative and aesthetic layers, the analysis of the role of leotard costume type clearly explains why practice-clothes leotard ballets should be seen as a significant sub-genre of contemporary ballet, the one which reveals much more than it excludes.

\section{ACKNOWLEDGEMENTS}

The author is grateful to Dominik Mentzos, Alexandra Scott and The Forsythe Company for the support with photographic material of Ballett Frankfurt. Thank you to Catherine Chang and The National Ballet of Canada as well as to Maria Børja and the Norwegian National Ballet for the photographic materials of these companies. I am indebted to the following dancers, choreographers, designers, historians and other interviewees for their generous support with information and feedback: Merrill Ashley, Todd Bolender, Theresa Buckland, Deborah Bull, Dana Caspersen, Marjory Fielding, William Forsythe, Stephen Galloway, Lynn Garafola, Holly Hynes, Jill Johnson, Zdenek Konvalina, Nehemiah Kish, Martine Lamy, Jane Pritchard, Geon van der Wyst and Xiao Nan Yu.

\section{REFERENCES}

Ashley, Merrill (2011), Skype interview, 28 October.

$\mathrm{Au}$, S. (1998), 'Vol.5: Practice clothes', in S.J. Cohen (ed.), International Encyclopedia of Dance, Oxford: Oxford University Press, pp. 240-243.

Balanchine, G. (1992), 'Marginal notes on the dance', in W. Sorell (ed.), Dance Has Many Faces, 3rd rpt., Chicago: Chicago Review Press, pp. 35-43.

Banes, S. (1998), Dancing Women: Female Bodies on Stage, London: Routledge. Bolender, Todd (2005), telephone interview, 23 February.

Bull, Deborah (2011), telephone interview, 29 June.

Calegari, Maria (2011), telephone interview, 14 December.

Caspersen, D. (2000), 'It starts from any point', in S. Driver (ed.), Choreography and Dance: William Forsythe, vol. 5 (3), Reading: Harwood Academic Publishers, pp. 25-40.

(2014), e-mail correspondence, 22 June.

Danilova, A. (1986), Choura: Memoirs of Alexandra Danilova, New York: Knopf. Fielding, Marjory (2010), telephone interview, 15 October.

Galloway, Stephen (2011), telephone interview, 17 July.

Garafola, L. (2005), 'Dance in the city: Toward an American dance', in Legacies of Twentieth-Century Dance, Middletown: Wesleyan University Press, pp. 231-55.

The George Balanchine Foundation (2007), 'The Balanchine Catalogue', The George Balanchine Foundation Web Presentation, http://www. balanchine.org/balanchine/display_result.jsp?id=262\&sid=concerto $\% 20$ barocco\&searchMethod=exact. Accessed 29 August 2014.

Greskovic, R. (1998), Ballet 101: A Complete Guide to Learning and Loving the Ballet, New York: Hyperion. 
Hargreaves, J. (1994), Sporting Females: Critical Issues in the History and Sociology of Women's Sports, London: Routledge.

Hynes, Holly (2010), e-mail correspondence, 24 October.

Jordan, S. (2007), 'George Balanchine's Stravinsky: Collaboration as challenge', in Stravinsky Dances: Re-visions Across a Century, London: Dance Books, pp. 158- 256.

Johnson, Jill (2008), telephone interview, 30 December.

- (2010), e-mail correspondence, 15 October.

Kersley, L. and J. Sinclair (1973), 'Leotard', A Dictionary of Ballet Terms, 3rd. ed., London: Adam \& Charles Black, p.78.

Kish, Nehemiah (2011), personal interview, 16 June, London, United Kingdom.

Konvalina, Zdenek (2009), personal interview, 23 October, Toronto, Canada.

Lamy, Martine (2011), telephone interview, 15 April.

Mason, F. (1991), I Remember Balanchine: Recollections of the Ballet Master by Those who Knew Him, New York: Doubleday.

Misler, N. (1991), 'Designing gestures in the laboratory of dance', in N. Van Norman Baer (ed.), Theatre in Revolution: Russian Avant-Garde Stage Design 1913-1935, London: Thames and Hudson, pp. 156-73.

- (2000), 'Dressing up and dressing down: The body of the avant-garde', in J. Bowlt (ed.), Amazons of the Avant-Garde, New York: The Solomon R. Guggenheim Foundation, pp. 95-108.

Moore, L. (1960), 'Practice clothes - then and now', Ballet Annual, 14 , pp. $118-24$.

Nye, E. (2011), Mime, Music and Drama on the Eighteenth Century Stage: The Ballet d'action, Cambridge: Cambridge University Press.

Pritchard, Jane (2010), e-mail correspondence, 27 October.

Reynolds, N. (1999), 'Listening to Balanchine', L. Garafola (ed.), Dance for the City: Fifty Years of the New York City Ballet, New York: Columbia University Press, pp. 153-68.

Siegel, M. (1985), 'Agon', in The Shapes of Change: Images of American Dance, Berkeley and Los Angeles: University of California Press, pp. 227- 33.

Siegmund, G. (1999) 'An Interview with William Forsythe', Dance Europe, August/September, pp. 12-17.

Souritz, E. (1990), Soviet Choreographers in the 1920s, Durham and London: Duke University Press.

(1992), 'Constructivism and dance', in N. Van Norman Baer (ed.), Theatre in Revolution: Russian Avant-Garde Stage Design 1913-1935, London: Thames and Hudson, pp. 129-43.

Sparshott, F. (1995), 'Some aspects of nudity in theatre dance', Dance Chronicle, 18: 2, pp. 303-10.

Toepfer, K. (1997), Empire of Ectasy: Nudity and Movement in German Body Culture, 1910-1935, Berkeley and Los Angeles: University of California Press.

Tomic-Vajagic, T. (2012), 'The dancer's contribution: Performing plotless choreography in the leotard ballets of George Balanchine and William Forsythe', unpublished Ph.D. thesis, London: Dance Studies, University of Roehampton.

Tusa, J. (1999) 'Interview with William Forsythe', The John Tusa Interviews, BBC Radio 3, http://www.bbc.co.uk/radio3/johntusainterview/ forsythe_ transcript.shtml. Accessed 12 June 1999.

Van der Wyst, Geon (2010), personal interview, 23 September, Toronto, Canada. 
Victoria and Albert Museum (2014), 'Jules Léotard', Theatre Collection of the Victoria and Albert Museum, http://www.vam.ac.uk/content/people-pages/ jules-leotard. Accessed 29 August 2014.

Williams, J. (2012), 'Aquadynamics and the athletocracy: Jennie Fletcher and the British women's $4 \times 100$ metre Freestyle Relay Team at the 1912 Stockholm Olympic Games', Costume, 46: 2, pp. 145-16.

Yu, Xiao Nan (2009), personal interview, 23 October, Toronto, Canada.

\section{SUGGESTED CITATION}

Tomic-Vajagic, T. (2014), 'The dancer at work: The aesthetic and politics of practice clothes and leotard costumes in ballet performance', Scene 2: 1+2, pp. 89-105, doi: 10.1386/scene.2.1-2.89_1

\section{CONTRIBUTOR DETAILS}

Tamara Tomic-Vajagic is a lecturer in Dance Studies at the University of Roehampton, London, where she also received her Ph.D. in 2012. Her research focused on the dancer's agency in the plotless choreography by George Balanchine and William Forsythe. Tamara's background is in visual arts. She holds an undergraduate degree in Fine Arts from the University of Arts Belgrade (Serbia) and her M.A. Dance from York University, Toronto (Canada). Currently her research concerns concepts of visual culture in dance and the creative contribution of the performer in the contemporary theatre dance forms, including ballet. In June 2013 in London she co-organized The Forsythe Company at Work, a collaborative research event featuring The Forsythe Company, University of Roehampton, supported by Sadler's Wells. Her forthcoming publications include the study of portraiture and self-portraiture in visual arts and dance performance (Performance Research, 2014), as well as several lexicon entries in the first dance encyclopedia published in Serbian language.

Contact: University of Roehampton, Dance Department, Lawrence Building, Froebel College, Roehampton Lane, London, SW15 5PJ, UK.

E-mail: tamara.tomic-vajagic@roehampton.ac.uk

Tamara Tomic-Vajagic has asserted her right under the Copyright, Designs and Patents Act, 1988, to be identified as the author of this work in the format that was submitted to Intellect Ltd. 


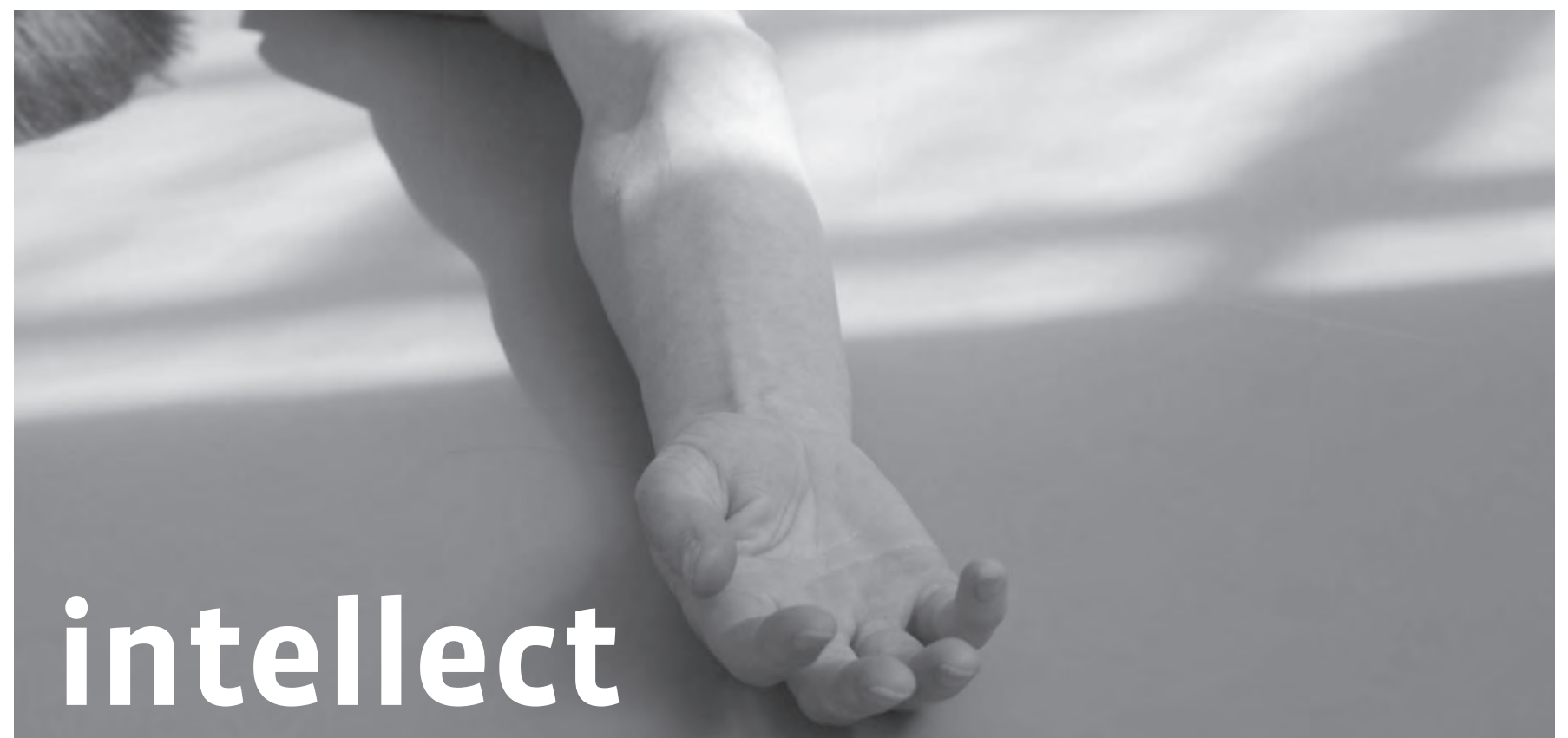

www.intellectbooks.com

\section{Choreographic Practices}

ISSN 2040-5669 | Online ISSN 2042-5677

1 issues per volume | Volume 4, 2013

\section{Aims and Scope}

Choreographic Practices operates from the principle that dance embodies ideas and can be productively enlivened when considered as a mode of critical and creative discourse. The journal provides a platform for sharing choreographic practices, inquiry and debate.

\section{Call for Papers}

Choreographic Practices is an international, peer-reviewed, bi-annual journal. Contributions are invited that articulate choreography from a diverse range of perspectives. We are especially interested in receiving articles that address research-led movement practices that are interdisciplinary and experimental in nature. Selected issues will also be thematically arranged. Choreographic Practices publishes both conventional and alternative modes of writing, including performative and visual essays

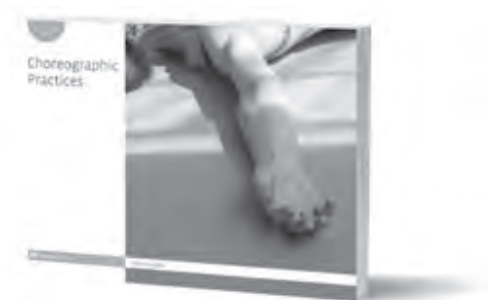

\section{Editors}

Vida L. Midgelow Middlesex University choreographicpractices@live.co.uk

Jane M. Bacon

University of Chichester

choreographicpractices@live.co.uk 